\title{
CLEFT LIP AND PALATE SURGERY: PREVALANCE OF INTRAOPERATIVE AIRWAY COMPLICATIONS IN A TERTIARY CENTER IN NEPAL
}

\author{
Thapa $A S,{ }^{1 *}$ Yadav $R K^{1}$
}

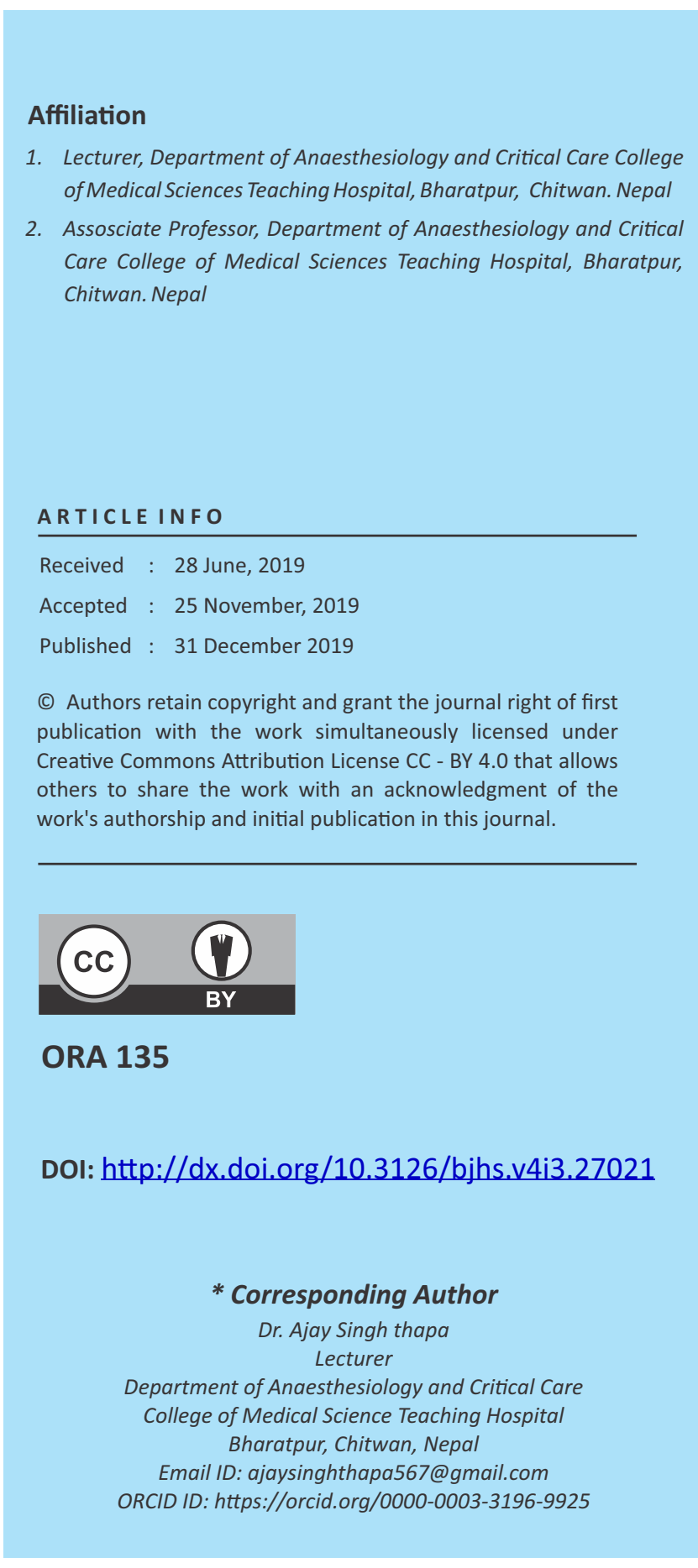

\section{Citation}

Thapa AS, Yadav RK. Cleft Lip and Palate Surgery: Prevalance of Intraoperative Airway Complications in a Tertiary Center in Nepal. BJHS 2019;4(3)10: 805-808.

\section{ABSTRACT}

\section{Introduction}

Cleft lip and palate is one of the most common congenital malformations. Different syndromes have been described in association with cleft lip and palate, some of which have considerable anesthetic implications, and many involve potential airway problems.

\section{Objective}

This study aimed to find the incidence of airway complications during cleft surgeries.

\section{Methodology}

The descriptive cross sectional study was conducted in College of Medical Sciences and Teaching Hospital, Bharatpur, Chitwan, Nepal over a period of one year from March 2017 to February 2018. All the 146 patients received general anesthesia. The parameters studied were incidence of difficult maskventilation, difficultintubation, laryngospasm, bronchospasm, aspiration of blood and secretion. Univariate analysis of demographic and occurrence of complications was done.

\section{Result}

A total of 146 patients underwent cleft surgery over the study duration out of which $42(28.76 \%)$ were female and 104 (71.23\%) were male. Isolated cleft lip was seen in 104 (71.23\%) patients among whom $42(28.76 \%)$ had right sided, 50 (34.24\%) had left sided and 12 (8.21\%) had bilateral cleft lip. Isolated cleft palate was seen in $12(8.21 \%)$ patients. Combined cleft lip and palate was seen in $30(20.54 \%)$ patients. Prevalence of difficult mask ventilation, difficult laryngoscopy, difficult intubation, incidence of bleeding during intubation, bronchospasm and post extubation laryngospasm were 4 $(2.73 \%), 11(7.53 \%), 6(4.10 \%), 2(1.36 \%), 2(1.36 \%)$ and $4(2.73 \%)$.

\section{Conclusion}

In cleft repair surgeries, difficult laryngoscopic view is the most common problem followed by difficult intubation and difficult mask ventilation. Complications like laryngospasm, bronchospasm and laryngoscopy related bleeding are not uncommon. Vigilant perioperative preparation and continuous monitoring is essential to prevent complications during cleft repair surgery in paediatric patients.

\section{KEYWORDS}

Anesthesia, Cleft lip, Cleft Palate, Intraoperaitve Airway Complications 


\section{INTRODUCTION}

The presence of a cleft lip, cleft palate or both has a huge impact on the life of an individual and the family. Cleft lip and palate (CLP) are one of the most common congenital malformations. The incidence of CLP worldwide is 1 in 700 live births and it is nearly 1 in 500 in India. ${ }^{1}$ The prevalence of CLP in Nepal is not exactly known but in a retrospective study 51 clefts $(0.16 \%)$ were identified among 30,952 live births. ${ }^{2}$ Both cleft lip and palate occur as a result of defects in palatal growth during the first trimester. Surgery aims to correct the anatomically obvious cleft lip, augment normal dento-alveolar development and lead to effective palatal function. ${ }^{3}$ Over 150 syndromes have been described in association with cleft lip and palate but fortunately all are rare. The most well known of these are the Pierre Robin, Treacher Collin and Goldenhar syndromes and Klippel-feil syndromes. ${ }^{4}$ Various studies have evaluated factors associated with perioperative airway related complications during cleft repair surgeries such as difficulty in placement of laryngoscope blade due to anatomical defect, the presence of associated facial deformities like micrognathia and the degree of deformity such as bilateral clefts with higher risk of adverse events. ${ }^{5-7}$ Recurrent respiratory tract infections cause constant irritation, increases airway reactivity and may result in laryngospsam and bronchospasm in children with clefts. ${ }^{8}$ Incidence of perioperative respiratory complication in healthy children is $4 \%$ which increases to $23 \%$ in patients with symptoms of common cold. ${ }^{9}$ This study aims to find the incidence of airway related complications during cleft surgeries in paediatric population in our setup.

\section{METHODOLOGY}

The descriptive cross sectional study was conducted in College of Medical Sciences, Bharatpur, Chitwan, Nepal. The study covers 146 cases operated for cleft lip and palate repair over a period of one year from March 2017 to February 2018. The study was conducted after taking ethical clearance from the institutional review committee. After well informed assent, all the participants were initially screened by the operating surgeon, pediatrician and anesthesiologist a day before surgery. After the clearance from the team, participants were included in the study. Inclusion criteria were age above three months for cleft lip surgery and above six months for cleft palate surgery, and hemoglobin above $10 \mathrm{gm} / \mathrm{dl}$ for all participants. Participants with recent history or active upper respiratory tract infection with history of recent fever and any abnormal findings during auscultation of chest were excluded from the study. Participants were kept nil per oral for any solid food for at least six hours but were allowed to feed glucose containing liquids up to two hours prior to surgery. All the participants received general anesthesia. All the participants were pre-medicated with intravenous (IV) Inj. Atropine $0.01 \mathrm{mg} / \mathrm{kg}$ and IV Inj. Midazolam $0.05 \mathrm{mg} / \mathrm{kg}$. All participants were induced with IVInj. Ketamine $1 \mathrm{mg} / \mathrm{kg}$, Inj.Propofol $1 \mathrm{mg} / \mathrm{kg}$ and halothane, and intubation with appropriate oral Ring Adair Elwyn (RAE) endotracheal tube was facilitated with IV Inj. Succinylcholine $1.5 \mathrm{mg} / \mathrm{kg}$. In all the participants anesthesia was maintained with halothane or is oflurane and muscle relaxation with IV Inj.vecuronium $0.1 \mathrm{mg} / \mathrm{kg} /$ hour. Analgesia was maintained with inj. Pethidine $1 \mathrm{mg} / \mathrm{kg}$ and supplemented with IV Inj. Paracetamol $15 \mathrm{mg} / \mathrm{kg}$. At the end of each procedure, oral suctioning was done under laryngoscopy and neuromuscular blocker was reversed with IV Inj. Neostigmine $0.06 \mathrm{mg} / \mathrm{kg}$ along with Inj. Glycopyrrolate $0.2 \mathrm{mg} / \mathrm{kg}$. After reversal, participants were observed and extubated in presence of adequate tidal volume, presence of eye opening, purposeful patient movement, low end tidal anesthetic agent concentration and response to physical or verbal stimulation.

During the induction, maintenance, reversal of anesthesia and recovery, difficult mask ventilation, difficult laryngoscopy, difficult intubation, bronchospasm and post extubation laryngospasm were looked for and noted. Laryngoscopy views were graded and the one with Cormack and Lehane grade three and four were taken as difficult laryngoscopy. Successful intubation with one or two attempts was graded as easy, three or four attempts as difficult and when was not possible even after four attempts were graded as failed. Complications when appeared were managed accordingly to protocol of the department. After the surgery, all the participants were transferred to post-operative recovery room where all the participants were monitored by the attending nurse. Each participant was observed carefully, and handed over to their parents after 30 minutes in the recovery room but not to be discharged until next 24 hours.

Demography of the participants and incidence of any complications were recorded in Microsoft Office Excel. Despriptive analysis was done using Statistical package for Social Sciences (SPSS ${ }^{\mathrm{TM}}$ ) software version 20.

\section{RESULT}

A total of 146 participants underwent cleft surgery over a period of one year, out of which 42 (28.76\%) were female and 104 (71.23\%) were male. Isolated cleft lip was seen in 104 participants among whom $42(28.76 \%)$ had right sided, 50 (34.24\%) had left sided and 12 (8.21\%) had bilateral cleft lip. Isolated cleft palate was seen in 12 (8.21\%) participants. Combined cleft lip and palate was seen in 30 (20.54\%) participants. From the combined cleft lip and palate participants, seventeen underwent cleft lip surgery and thirteen underwent palatoplasty. Therefore, there were 121 lip reconstruction surgeries and 25 palatoplasties. Average age of the participants undergoing cleft lip surgery was $6.72 \pm$ 1.82 months and average weight was $6.28 \pm 0.97 \mathrm{~kg}$. Similarly, the average age of participants undergoing cleft palate surgery was $11.76 \pm 2.93$ months and average weight was $10.19 \pm 1.16 \mathrm{~kg}$. The incidence of difficult mask ventilation and difficult laryngoscopy was seen in four (2.73\%) and 11 (7.53\%) participants. Difficult intubation, bleeding during laryngoscopy, bronchospasm and post extubation laryngospasm was experienced in $6(4.10 \%), 2$ (1.36\%), 2 (1.36\%) and4 (2.73\%) participants. 
Table 1: Demographic profile of the participants. $(\mathrm{N}=146)$

$\begin{array}{lccc}\text { Type } & \text { Male } & \text { Female } & \text { Percentage } \\ \text { Right cleft lip } & 26 & 16 & 28.76 \\ \text { Left cleft lip } & 38 & 12 & 34.24 \\ \text { Bilateral cleft lip } & 8 & 4 & 8.21 \\ \text { Combined lip and palate } & 24 & 6 & 20.54 \\ \text { Isolated cleft palate } & 8 & 42 & 8.21 \\ \text { Total } & 104 & 400\end{array}$

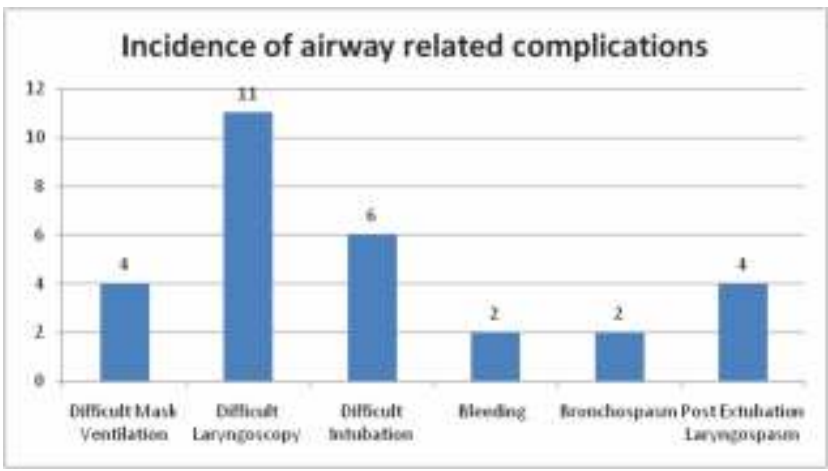

Figure 1: Incidence of airway related complications.

\section{DISCUSSION}

In our study, incidence of difficult mask ventilation was observed in four participants (2.73\%). Management options in such situation include turning the patient lateral or semiprone, use of nasal or oral airways and laryngeal mask airways. If maneuvers and airway devices fail to maintain secure airway, consideration should be to wake the patient and postpone the surgery. Surgical airway in these cases are difficult but may be needed to secure and maintain airway. ${ }^{10}$ Difficult laryngoscopy and intubation are associated with cleft repair surgeries especially with complete cleft palate and bilateral cleft lip due to retrognathia and the protruding premaxilla respectively. ${ }^{11}$ In our study, the most common problem was difficulty with laryngoscopy followed by intubation. We observed that difficult laryngoscopy was more common in children with left sided clefts. Eleven participants (7.53\%) experienced difficult laryngoscopy, all of whom had left sided cleft lip. In a study by Gunawardana, laryngoscopy was easy ( grade I and II) in 92.62\%, difficult (grade III and IV) in $7.38 \%$, difficult intubation in $8.38 \%$, easier intubation in $90.62 \%$ and failed intubation in $1 \%{ }^{12}$ In another study, Xueet al observed incidence of difficult laryngoscopy to be $4.77 \%$ and incidence of moderately difficult, difficult and failed intubation to be $1.02 \%, 0.91 \%$ and $0.102 \%$ respectively. ${ }^{5}$ They observed that incidence of difficult laryngoscopy was closely related to age, site and degree of deformity. One of the problems during laryngoscopy is falling of the laryngoscopy blade inside the cleft resulting in difficult laryngoscopy view and trauma. Gauze used to fill the cleft cavity prevents the movement of the blade inside the cleft and helps in better laryngoscopy view as does the lateral or molar approach and external laryngeal manipulation. ${ }^{10}$
In our study the incidence of difficult intubation was $4.10 \%$, all of whom had left sided cleft lip. In a study by Karkiet al, theincidence of difficult intubation was $3.86 \%$ and incidence of failed intubation was $0.17 \% .{ }^{13}$ In another study conducted by Senand Senetal, they experienced difficult intubation in $6.2 \%$ of the patients. ${ }^{11}$ They suggested using RAE (south facing) tube for cleft repair surgeries. Gentle laryngeal pressure backward, upward and right wards results in better laryngoscopy view in these cases. Lateral traction at the angle of mouth in the right side of the patient improves the space for introduction of the endotracheal tube into the mouth and also improves the visualization during insertion of the tube through the glottis.

In children with cleft lip and palate, recurrent nasal cavity and respiratory tract infections along with recurrent aspiration causes constant irritation and increases airway reactivity resulting in high incidence of laryngospasm and bronchospasm in these patients. ${ }^{8}$ In our study, bronchospasm was experienced in two (1.36\%) participants with cleft palate. In a study by Kulkarniet al, the incidence of bronchospasm was $0.5 \%$ only. ${ }^{14}$ In another study by Desaluet al, they observed a higher incidence of airway related complications during cleft repair surgeries. ${ }^{15}$ They reported an incidence rate of bronchospasm to be $4 \%$ which was only seen in participants with cleft palate. Causes of increased peak airway pressure are most commonly due to either kinking of endotracheal tube, soiled airway or bronchospasm. Bronchospasm is most common during induction of anesthesia. Bronchospasm during induction of anesthesia is most commonly caused by airway irritation related to intubation such as aspiration and inadequate depth of anesthesia. ${ }^{16}$ During our study, the secases responded to increasing the depth of anesthesia with halothane and IV Propofol $1 \mathrm{mg} / \mathrm{kg}$ followed by airway suctioning through endotracheal tube to remove secretions and inhalational salbutamol via metered dose inhalation (4-8 puffs) through the endotracheal tube. Exclusion of other life-threatening conditions such as pulmonary edema, pulmonary embolism, foreign body aspiration and tension pneumothorax is equally essential. ${ }^{16}$

Laryngospasm is one of the most common perioperative airway related adverse events in pediatric patients. In our study, four $(2.73 \%)$ participants had post extubation laryngospasm. All thefour participants were operated for cleft palate and the culprit here was observed tobe the remnant blood and clot in the naso-pharyanx that later 
drained to irritate the larynx. None of the four participants had active bleeding. Tay et al, in their audit of 10000 cases observed incidence of laryngospasm to be $35.7 \%$ out of 297 critical airway related incidences. ${ }^{17}$ Sen and Senet al observed that incidence of laryngospasm was $1 \%$ and Kulkarni et al observed the incidence to be $0.3 \% .{ }^{11,14}$ Laryngospasm is a life threatening complication which requires rapid resuscitation. Management of laryngospasm includes maneuvers like Esmarch Heiberg maneuver (jaw thrust) and gentle pressure in the mid thorax, continuous positive pressure ventilation with $100 \%$ oxygen and concomitant use of pharmacological agents like Succinylcholine, Propofol and different opioids. ${ }^{18}$ In our study, to avoid aspiration of blood and clot from recent surgery, these patients were immediately intubated after bolus of Inj. Atropine $0.01 \mathrm{mg} / \mathrm{kg}$ and Inj. Succinylcholine $(1.5 \mathrm{mg} / \mathrm{kg})$, followed by suctioning of oropharynx and trachea and later extubated without any consequences.

Laryngoscopy related traumatic bleeding was experienced in $2(1.36 \%)$ patient. These were cases of complete cleft lip, in which during laryngoscopy, laryngoscopy blade injured the alveolus and resulted in bleeding. After intubation, immediate suction over the wound and gentle compression applied with gauge over the alveolus or lip until the bleeding stopped is sufficient in these scenarios.

\section{CONCLUSION}

Incidence of airway complications is high in cleft repair surgeries. Difficult laryngoscopy followed by difficult intubation and difficult mask ventilation are common problems faced by an anesthetist. Life threatening complications like laryngospasm and bronchospasm are not uncommon. Careful preoperative preparation of patients, airway management equipment, anesthetic plan and vigilant anesthetic supervision is essential to avoid complications.

\section{LIMITATIONS OF OUR STUDY}

Since the study includes participants below two years of age and anesthetic management may vary in different setups, incidence observed in our study cannot be generalized.

\section{ACKNOWLEDGMENT}

I will like to thank all the residents for their help during the study and data collection.

\section{REFERENCES}

1. Selvia R, Saranya GR, Murthy BJ,Fa AM, Paula SFD et al.Chromosomal abnormalities in individuals with cleft lip or cleft palate. Sri Ramachandra journal of medicine 2009;2:21-4.DOI: 10.4103/09700358.53004

2. Singh VP, Sagtani R, Sagtani A. Prevalence of cleft lip and cleft palate in a tertiary hospital in eastern Nepal. Mymensingh Med J 2012;21(1): 151-4. PMID:22314472

3. Hardcastle T. Anaesthesia for repair of cleft lip and palate. J Perioper Pract 2009;19:20-PMID:19260357DOI: 10.1177/175045890901900102

4. Hatch DJ. Airway management in cleft lip and palate surgery. BJA 1996;76:755-6.DOI: https://doi.org/10.1093/bja/76.6.755

5. Xue FS, Zhang GH, Li P et al. The clinicalobservation of difficult laryngoscopy and difficult intubation in infants with cleft lip and palate.PediatrAnesth2006; 16: 283 - 9.https://doi.org/10.1111/j. 1460-9592.2006.01937.x

6. NargozianC. The airway in patients with craniofacialabnormalities PediatrAnesth2004;14:53-9. PMID: 14717875

7. Frilles $\mathrm{T}$, Homann $\mathrm{C}, \mathrm{Meyer} \mathrm{U}$ et al. Perioperative complications in infant cleft repair. Head \&FaceMedicine2007; 3: 9 PMID:17280602 PMCID:PMC1805427 DOI:10.1186/1746-160X-3-9

8. Murat I, Constant I, Maud'Huy H. Perioperativeanaesthetic morbidity in children: a database of 24165 anaesthetics over a 30-month period. PediatrAnesth2004; 14: 158-66. PMID: 14962332

9. Takemura H, Yasumoto K, ToiTetal.Correlation of cleft type with incidence of perioperative respiratory complications in infantswith cleft lip and palate. PediatrAnesth2002; 12:585-8.PMID:12358652
10. Somerville N, Fenlons. Anaesthesia for cleft lip and palate surgery, Continuing Education in Anesthesia Critical Care \& Pain 2005;5(3):76-7.

11. Sen J, Sen B. Airway management: A comparative study in cleft lip and palate repair surgery in children. Anesthesia: Essay and researches 2014:8(1):36-40.DOI: 10.4103/0259-1162.128905

12. Gunawardana RH. Difficult laryngoscopy in cleft lip and palate surgery. BJA 1996; 76:7579.PMID:8679344 DOI:10.1093/bja/76.6.757

13. Karki SB, Rajbanshi LK, Ariyal B et al. Anesthesia for cleft lip and palate surgery: study from a hospital of eastern Nepal. BJHS 2017;2(1):12733.DOI: https://doi.org/10.3126/bjhs.v2i1.17288

14. Kulkarni KR, Patil MR, Shirke $A M$ et al. Perioperative respiratory complications in cleft lip and palate repairs: An audit of 1000 cases under 'Smile Train Project'. Indian J Anaesth2013;57(6):562-8.DOI: 10.4103/0019-5049.123328

15. Desalu I, Adeyemo W, Akintimoye M et al. Airway and respiratory complications in children undergoing cleft lip and palate repair. Ghana MedJ.2010;44(1):16-20. PMID:21326986PMCID: PMC2956308

16. Westhorpe RN, Ludbrook GL, Helps SC.Crisis management during anesthesia: bronchospasm. BMJ 2005;14:7.PMID:15933304 PMCID:PMC1744001DOI:10.1136/qshc.2002.004457

17. TayCLM, Tan GM, Ng SBA. Critical incidents in paediatric anesthesia: an audit of 10000 anaesthetics in Singapore. Pediatr Anesth 2001;11:711-8. PMID:11696149

18. Hernández-Cortez E. Update on the management of laryngospasm. J AnesthCrit Care Open Access 2018;8(2):1-6. DOI: 10.15406/ jaccoa.2018.08.00327 